\title{
Ortlepp Shears — Dynamic Brittle Shears of South African Gold Mines
}

\author{
G. van Aswegen ISS International, South Africa
}

\begin{abstract}
For many, Mr David Ortlepp will be best remembered for his detailed descriptions of the dynamic brittle shears, being the sources of some typical rockbursts in South African mines. In this paper the distinguishing features of these shears are reviewed and it is argued that they are sufficiently unique to warrant a special name - Ortlepp shears. Three examples are used to explain characteristic features of these shear zones, introducing the terms 'overshoot', 'shear zone wall lineations' and 'breakthrough shear ruptures' as part of the terminology describing the phenomenon. The once-off dynamic origin in strong, siliceous quartzites explains the lack of the classic shear zone fabrics described by Tchalenko (1970) and others.
\end{abstract}

\section{Introduction}

The benchmark paper of Gay and Ortlepp (1978) on the 'Anatomy of a mining induced fault zone' was published eight years after the occurrence of the associated seismic events in September 1970 at East Rand Proprietary Mines (near Johannesburg). The sources were exhumed, photographed and mapped in detail during 1974 and 1975, followed by microscopic studies of the fault 'rock' and a detailed description in that paper. A seismological study was published later (McGarr et al., 1979). Such detail studies have never since been attempted and is unlikely to be repeated because of the special circumstances of that case.

The phenomenon described in those papers has attracted the attention of several researchers, e.g. Wilson et al. (2005). The first order similarity to naturally occurring brittle shear zones allows general agreement about the basic origin of the structures. In terms of rockburst classification in the South African mining industry, these structures are commonly the sources of 'face parallel bursts', 'pillar abutment failure' and 'pillar foundation failure' and the driving forces and source mechanisms are generally well understood (e.g. Brummer, 1987; Jager and Ryder, 1999; Bosman and van Aswegen, 2003). When considering the details, however, there are lingering uncertainties of at least academic interest, some addressed here.

Unlike type localities of geological phenomena that can be visited again and again (e.g. pseudotachylite in the Vredefort Dome) the type example of Ortlepp shears, a mining phenomenon, will never be seen again and will exist only in Chapter 3.1.4. of the SAIMM's Monograph No. 9 (Ortlepp, 1997). As long as deep, hard rock mining is with us, the phenomenon will, however, repeat itself, hopefully not with tragic results as has often been the case in the past. Some characteristic features are explained using photographs from three rockburst case studies from South African gold mines. The first two (Figures 2(a) and 2(b)) involved longwall stope, face parallel shears. In the first case, a relatively simple shear was mined trough and well exposed in a roadway within the stope. Figure 2(b) involved a complex rockburst with two major shear zones, one ahead of the face and the other daylighting in the stope from the hangingwall. Figure 2(c) involved a tunnel that 'blew up' under virgin stress conditions, far from mining.

\section{Nomenclature}

A common nomenclature for the rather special structures is required for ease of communication. Despite Ortlepp's considerable linguistic skills, appropriate terminology as general reference to these features eluded him. Terms like 'mining induced fault zone' (Gay and Ortlepp, 1978), 'shear zone' (McGarr et al., 1979), 'shear fracture' (Brummer, 1987), 'burst fracture' (McGarr, 1971) 'shear rupture', 'dynamic rockburst rupture' (Ortlepp, 1997) and 'dynamic brittle shear' (Bosman and van Aswegen, 2003) have been used in literature. Even the miners who come across such features on a daily basis have no common terminology. One approach is to use a purely descriptive term that excludes interpretation plus an adjective to suggest the origin of the feature. Geologists, geotechnical engineers and seismologists tend to live in different semantic 
worlds. Since we deal with a macroscopic phenomenon most easily recognised from pictures in geological textbooks, a geological approach is preferable and the term 'dynamic brittle shear' seems appropriate. Despite some effort by Ortlepp himself using this term, however, it has not caught on, while the term 'Ortlepp shear' is fairly commonly used. It is therefore suggested here that an Ortlepp shear is a particular class of dynamic brittle shear defined by the 'definitive characteristics' listed by Ortlepp (2000).

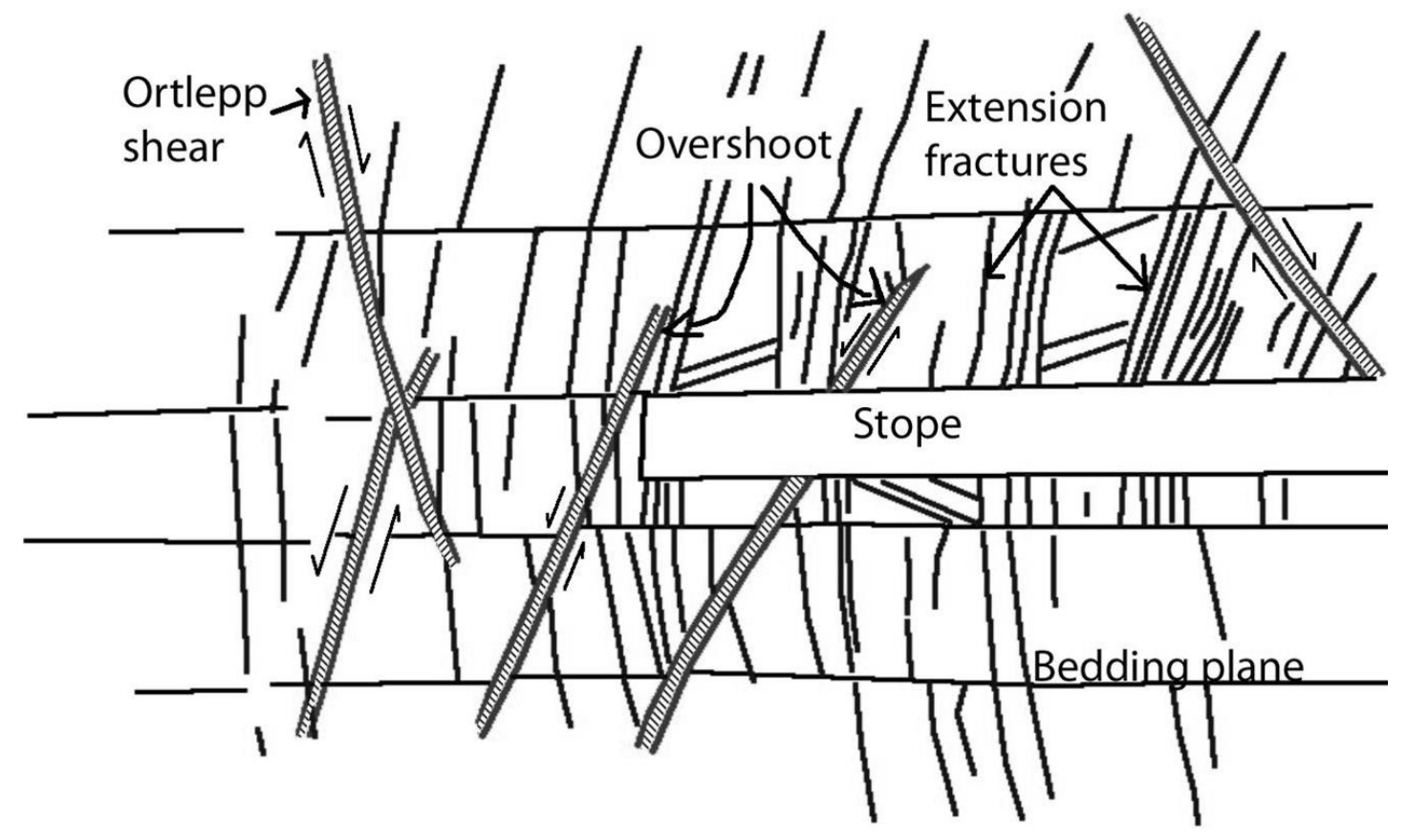

Figure 1 Schematic of a stope in a deep South African gold mine and its associated extension fractures and Ortlepp shears (re-drawn after Brummer, 1987)

\section{Geometric relations to mine openings}

In the standard description of fractures around tabular stopes in deep South African gold mines (Figure 1), a specific class of fractures are labelled 'Type II' fractures or simply 'shear fractures'. Since their origins are essentially the same as those of conjugate shears under tri-axial load, they differ in orientation from the more common extension fractures (tensile fractures) forming ahead of the advancing stope and yielding the bow wave fabric. Ortlepp shears are large shear fractures, associated with significant seismic events.

An Ortlepp shear would originate ahead of an advancing stope face (ideally a longwall face), always show normal displacement and would dip towards the stope face when in the hangingwall and dip away from the stope face when in the footwall. The occurrence of part of an Ortlepp shear in the 'wrong' orientation is ascribed to overshoot - the shear would, for example, initiate ahead of the stope face and below the reef horizon, and 'overshoot' by ending above the reef horizon (Figure 1).

\section{The internal structure}

Detailed descriptions of the shears are found in the publications referred to previously. The general appearance is that of a series of short shear and extension fractures arranged in an en-echelon formation along a long band defining a brittle shear zone. Ortlepp (2000) listed a number of 'definitive characteristics' of 'rockburst ruptures', most of which are addressed here. A couple of new terms are considered useful to fully describe the phenomenon.

\subsection{Shear zone wall lineations}

In the simplest form, the Ortlepp shear is defined only by a densely packed en-echelon sequence of extension fractures. The intersection lines formed where these fractures cross the shear zone wall, define very prominent lineations - “... probably the most definitively diagnostic feature of a rock burst rupture...”. 


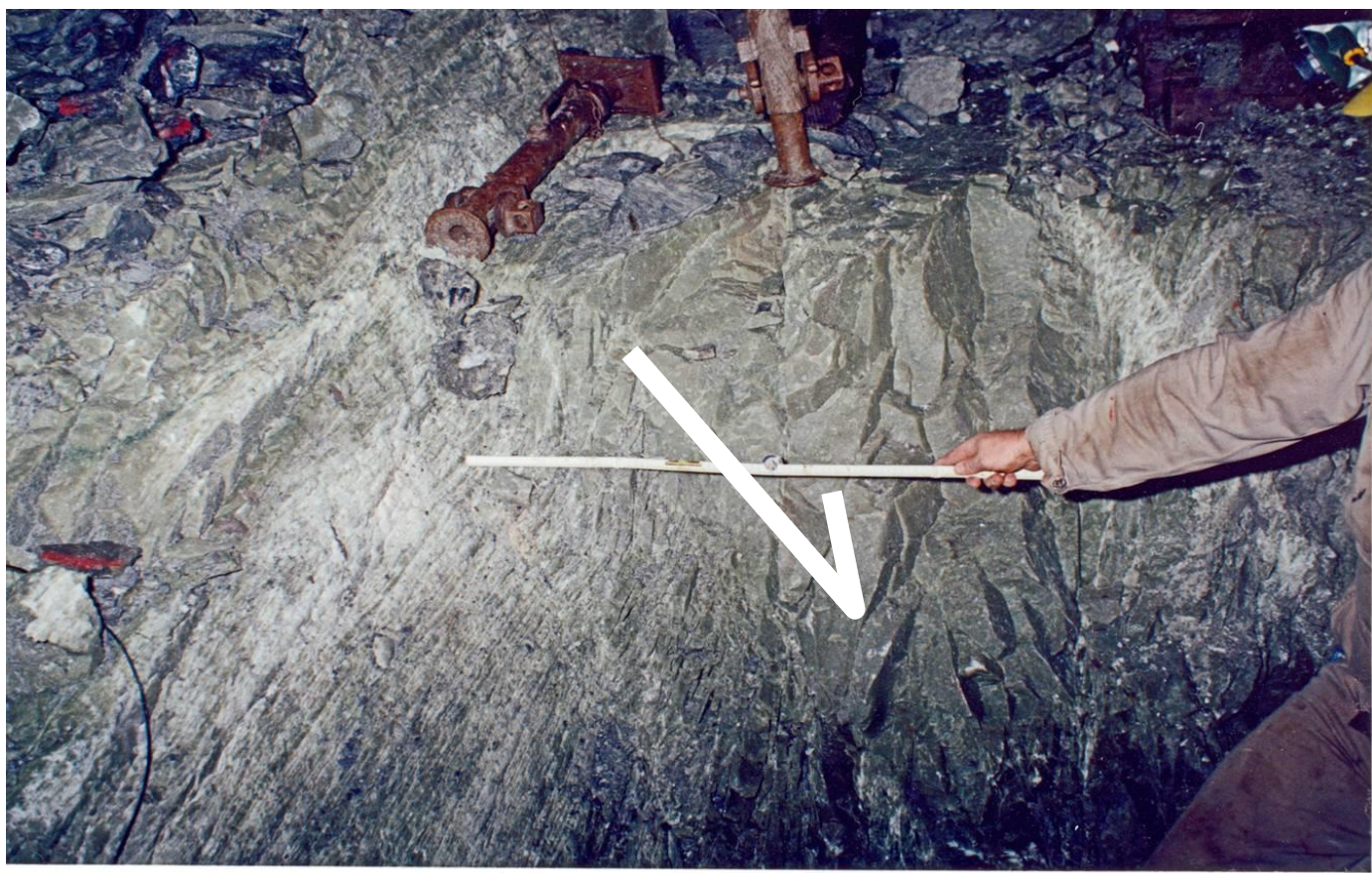

Figure 2 (a) Photograph of the end of a roadway in the footwall of a South African gold mine stope the end coincides with an Ortlepp shear zone wall, exposing the shear zone wall lineation (bottom left quarter of photograph). The arrow shows the direction of slip of the shear zone hangingwall

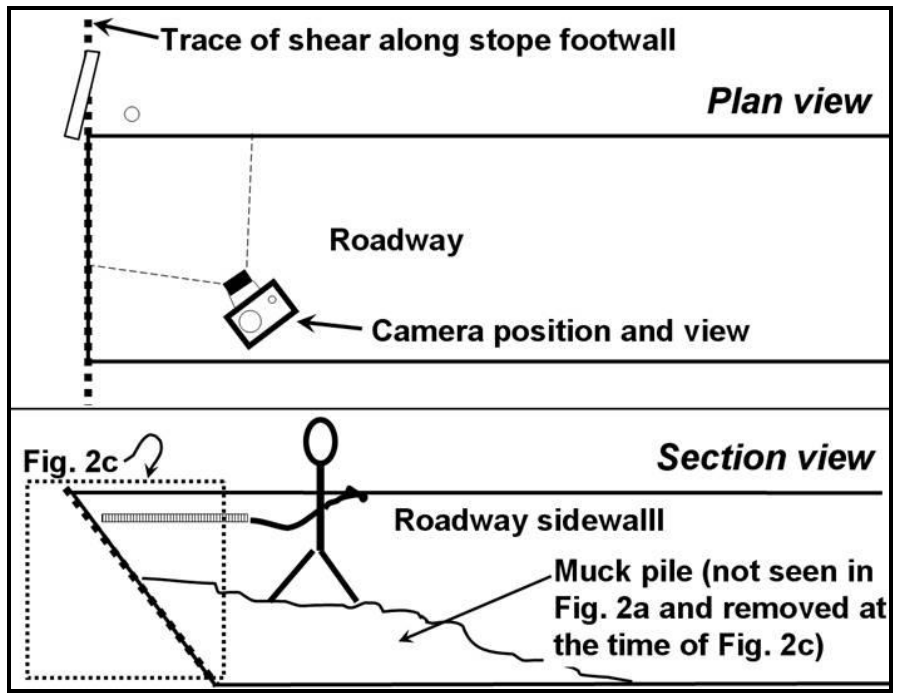

Figure 2 (b) Schematic plan and section views to explain Figure 2(a) and 2(c). The camera position and view is for the photograph in Figure 2(a) 


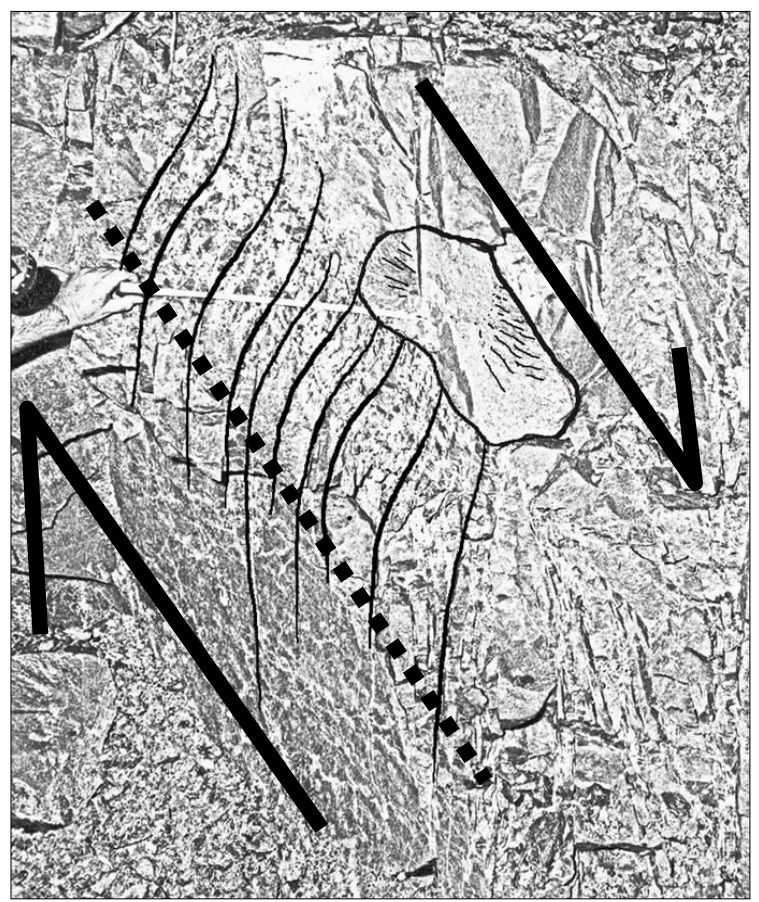

Figure 2 (c) View of the shear zone on roadway sidewall shown in Figure 2(a), but after some advance of the roadway. The broken line is the footwall of the shear zone along which the roadway end had been broken away in the case of Figure 2(a). An (unrelated?) extension failure surface, with plumose lineations is super-imposed on the shear zone fabric

Figure 2(c) shows curving extension fractures arranged in an en-echelon fashion that define the shear zone. The strong linear fabric shown in Figure 2(a) results from the intersection of the extension fractures with the footwall of the shear zone. Note the absence of breakthrough shear ruptures. The shear zone is approximately $200 \mathrm{~mm}$ wide and the finite displacement is approximately $20 \mathrm{~mm}$.

The extension fractures are referred to as 'pinnate micro-joints' and the shear wall lineations as 'hackled' surfaces in several of the older publications. The angle between the shear zone wall and the extension fracture increases with the normal stress acting on the shear zone (e.g. Wibberley et al., 2000).

The shear zone wall lineations are, by definition, at right angles to the shear slip vector and thus at right angles to fault slip striations during breakthrough shear rupture (see Section 4.2). We note that, in this example, one of the 'most diagnostic' features of Ortlepp shears has a rather non-dramatic explanation and it does not require significant shear slip. It is suggested here that the reason we see shear zone wall lineations in Ortlepp shears is that the rock easily breaks away along these newly formed shear zones. In naturally occurring brittle shears of geological age we do not observe such features because, due to re-crystallisation of the fault rock and consequent different strength characteristics, the shear zones do not break along the same surfaces.

\subsection{Breakthrough shear ruptures}

The shear zone described previously (Figures 2(a) and (c)) is somewhat atypical in the sense that it does not display one of the other diagnostic features of the namely breakthrough shear ruptures ('through-going rupture' in the terminology of Wibberley et al., 2000). In the archetype Ortlepp shear, the shear zone consists of an intricate combination of en-echelon extension fractures and breakthrough shear rupture zones, the latter at a low angle to the shear zone itself in a Riedel-like geometrical configuration (see Tchalenko, 1970 and Logan et al., 1979 for definitions of Riedel features). It is along breakthrough shear rupture zones that rock pulverisation is commonly observed and along which significant displacement takes place (Figure 3b; Figure 4(c)). These would be the initiation zones for the 'through-going principle slip surfaces (PSS) which persist in a particular configuration for extended time periods and accommodate subsequent shearing' as described by Sibson (1986). 
We note here that Ortlepp shears consist mainly of two mechanistic elements, namely extension fractures and breakthrough shear ruptures. No other structural elements are required to describe them and it is argued that, due to the once-off generation of the complete structure during one seismic event in hard rocks with little or no micaceous minerals, we do not necessarily see the development of the classic elements of brittleductile shears such $R_{1}, R_{2}$, P- and Y-shears (Tchalenko, 1970; Logan et al., 1979).

\subsection{Conjugate sets}

In many places Ortlepp shears have been observed to consist of conjugate sets of shear bands, although one direction generally dominates (Figure 3). It appears that in the area directly ahead of the stope face, conjugate sets are more common, while further away into the hangingwall or footwall of the reef, the one set would dominate. This follows from the common understanding of the formation of shear fractures ahead of stopes as shown in Figure 1.

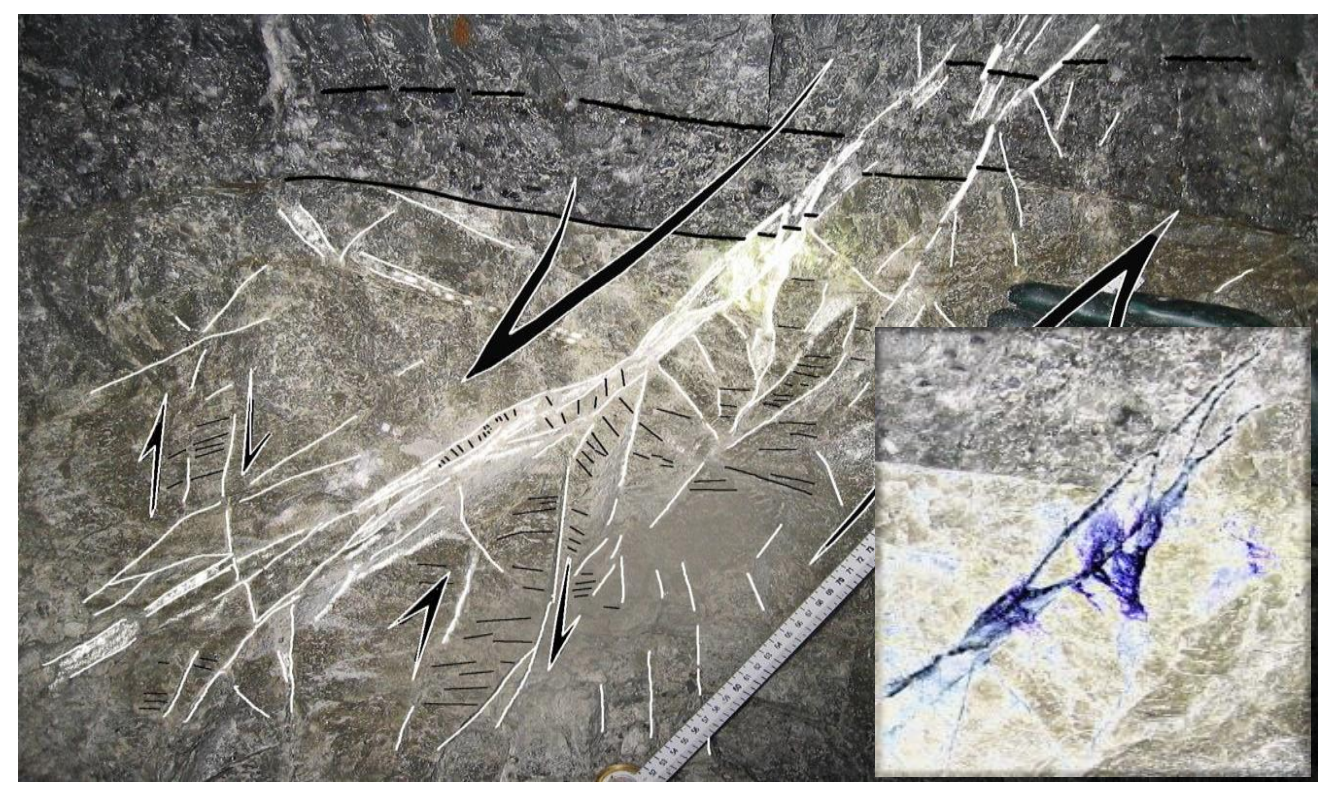

Figure 3 (a) A conjugate set of Ortlepp shears, the source of a seismic event some 6 metres ahead of a longwall stope (see Figure 3(b)). $200 \mathrm{~mm}$ of a clino rule is visible for scale. Finite normal displacement along the dominant shear is about $100 \mathrm{~mm}$. Dark parts of the inset accentuate the zones of breakthrough shear rupture and pulverisation

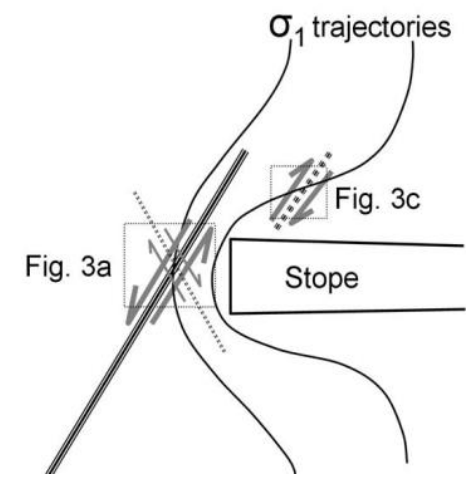

Figure 3 (b) Schematic of a conceptual model for the source and damage mechanisms for a particular rockburst (Case B). Note that, in the case of Figure 3(c), the sense of shear is different from the similarly positioned overshoot case shown in Figure 1 


\subsection{Rock flour}

Although fine coatings of powder-like material along fractures at mine openings is common, the volumes of rock flour found in Ortlepp shears are of a different order. In extreme cases, litres of the finely comminuted material can be scooped out of the shear zones by hand. Extreme characteristics of rock flour from an Ortlepp shear were discovered by the recent ground-breaking research of Reches and Dewers (2005) and Wilson et al. (2005). They found that most of the individual fragments in the rock flour can be as small as $0.3 \pm 0.2$ microns and they estimated volumetric strain rates of $10^{5} / \mathrm{s}$ to produce the material. In a stope where a rupture zone like that daylights, everything is covered with the fine white dust.

A characteristic of the internal fabric of the pulverulant zones is the absence of flux features. This contrasts with the flow banding commonly observed in mylonitised shear zones resulting from long-term creep. It is indeed the interpretation by Reches and co-workers that the formation of the rock flour is largely by dynamic, volumetric strain rather than shear. The extreme strain is associated with the 'deformation field close to the tip of a fast mode II fracture' (Reches and Dewers, 2005).

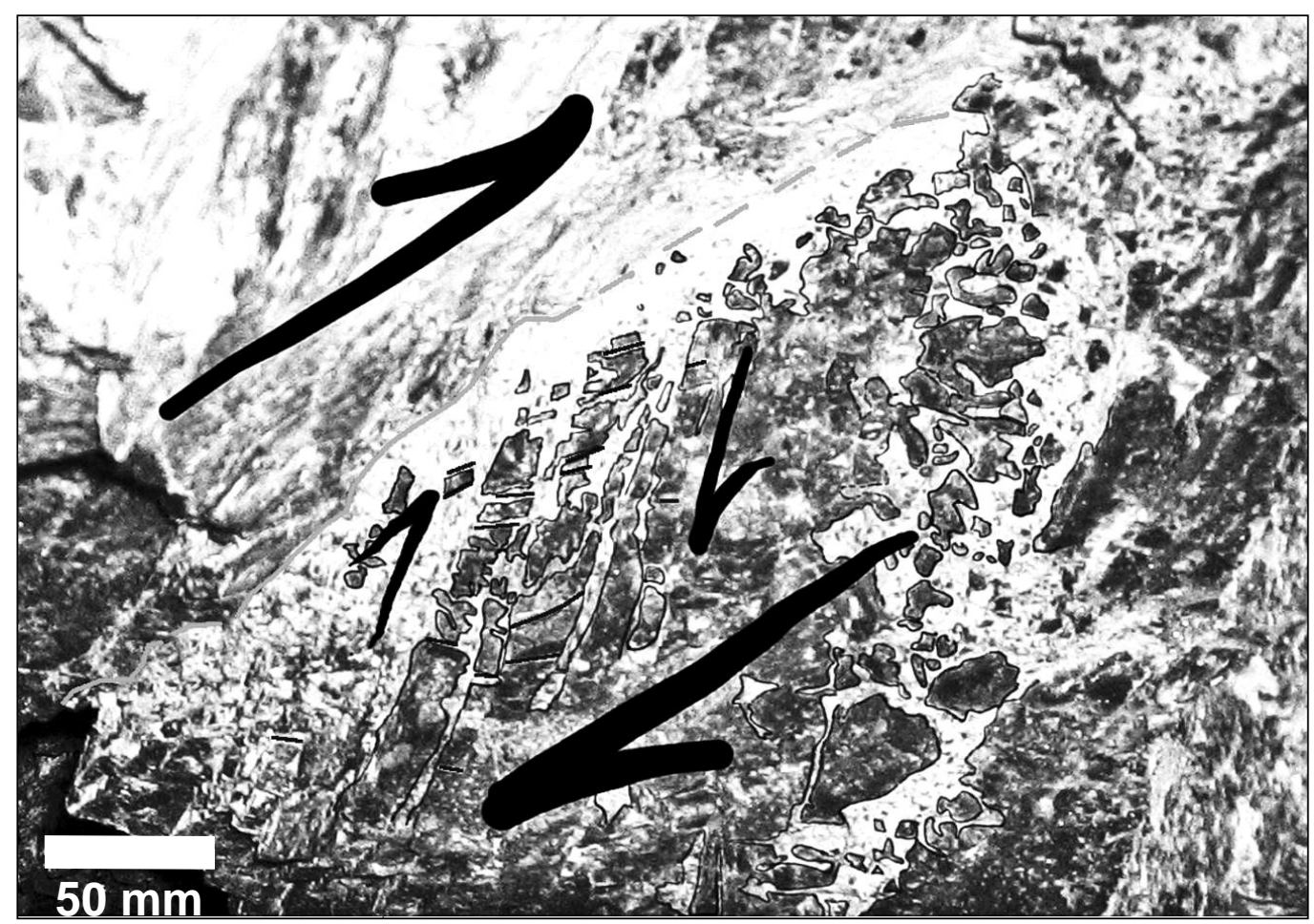

Figure 3 (c) Details of a reverse slip dynamic shear associated with co-seismic hangingwall failure during a particular rockburst (Figure 3(b)). In parts, rock fragments are 'drifting' in rock flour

An example of extreme pulverisation was found in the second shear zone of case B and shown here in Figure 3(c) (see Figure 3(b) for the position of this shear zone relative to the stope). The site response to the specific dynamic load imposed by a 'face parallel burst' (terminology as proposed in Jager and Ryder, 1999), involved stope hangingwall failure in the form of dynamic reverse slip along a newly form shear zone, causing partial stope closure (van Aswegen, in prep.). Figure 3(c) shows the internal structure of this reverse slip shear explained in Figure 3(b). In this case extreme shear and extensional strain rates resulted in the explosive pulverisation of the strong, siliceous quartzite resulting in a large volume of rock flour. Note that, despite the obvious shear displacement involved, no flow structure as such is present.

The structure shown in Figure $3 \mathrm{c}$ is, of course, not an Ortlepp shear in the classic sense because the displacement is reverse. It is not an overshot end of a footwall shear exposed by subsequent mining as explained in Figure 1. 


\subsection{Slip striations, plumose fractures}

By definition, slip associated with breakthrough shear ruptures should create fault slip striations - grooves left by frictional sliding. These are not generally described as part of the Ortlepp shear features due to our pre-occupation with the classic two-dimensional cross section view of the phenomenon.

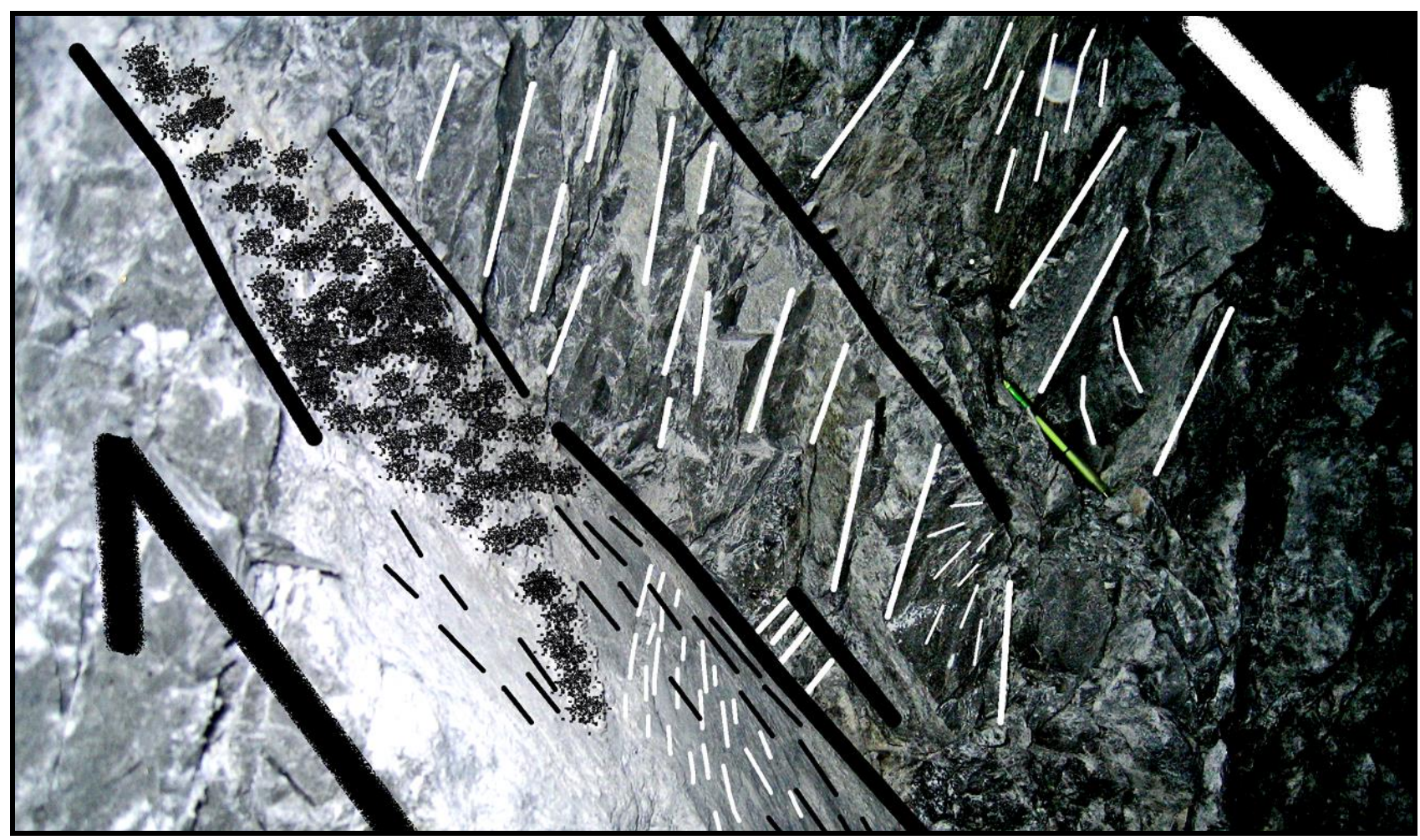

Figure 4 (a) Photograph of a complex dynamic brittle shear zone observed in the sidewall of a tunnel severely damaged by a local rockburst

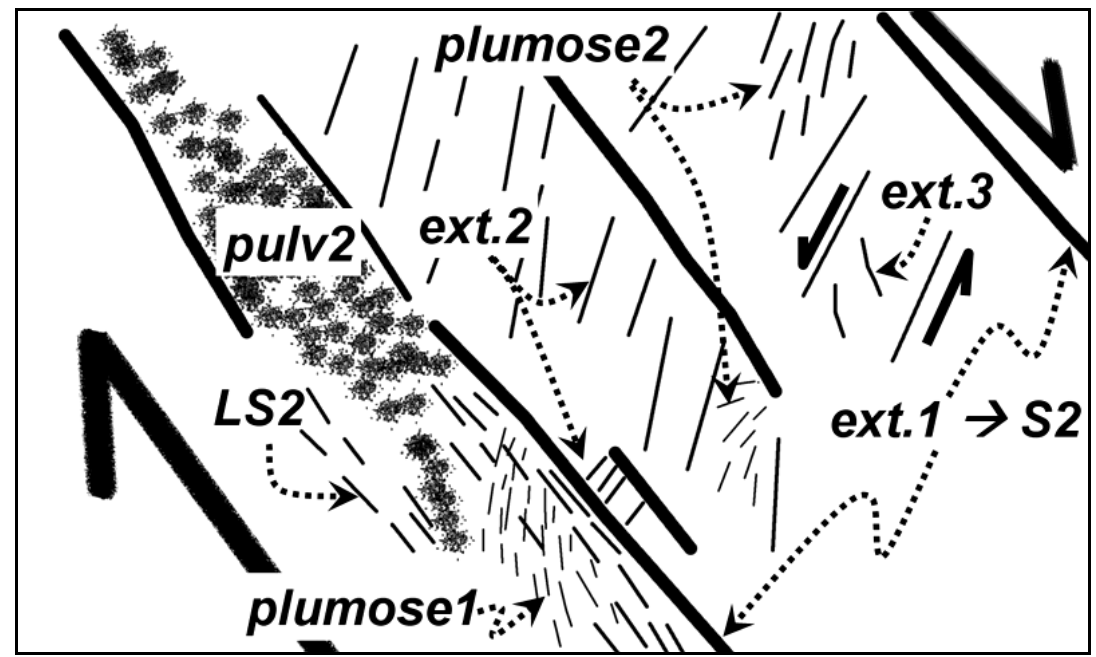

Figure 4 (b) Naming system for the different discontinuities marked in Figure 4(a)

Since extension fracturing form part of the dynamic brittle shear zone, one should observe the plumose striations common on other extension fractures such as joints indeed found when one looks closely enough. They are, however, difficult to capture photographically because of the small scales involved. Case C considered here (rockburst damaged tunnel far from mining, i.e. in the virgin stress field of approximately $2500 \mathrm{~m}$ below surface) afforded the opportunity capture images of such features because of the different scale of the associated shear zone (Figure 4). 
Careful 3D study using stereo-pair photographs allowed the recognition of several internal structures as shown in Figure 4. The interpretation given depends on the chronological sequence of events as visually deciphered and the assumption that it all happened as part of one dynamic sequence of events. The intense local rockburst damage is the circumstantial evidence suggesting (but not proving) the latter assumption.

From Figure 4 one can infer the following: in the immediate vicinity of the tunnel the stress distortion invokes low-angled shear traction such that a pre-existing metre-spaced discontinuity set is in the appropriate geometrical relation to fail in tension (ext. 1), yielding plumose structure with rupture propagation towards the mine opening (plumose 1). Partial loss of cohesion (in the proximity of the tunnel only) weakens the discontinuity set on a macro-scale allowing shear deformation to initiate in $\mathrm{R}_{1}$ style as indicated by the large arrows. This causes extension failure in the rock between the discontinuities (ext. 2) with their own plumose features (plumose 2). Slip along ext. 1 starts (s2) and evolves into 'breakthrough' shear rupture with pulverisation (pulv2) and slip striations (LS2), superimposed on the first plumose structures. A repeat of this process sees slight shear displacement along ext. 2 in $\mathrm{R}_{2}$ style, resulting in new extension fractures (ext. 3 ).

\section{Discussion}

The Ortlepp shears lack the complex internal shear zone fabric described from shear box experiments (e.g. Tchalenko, 1970; Logan et al., 1979). This is because those experiments were designed to explain the shear zones of geological age with long histories of shear displacement in rocks with clay or mica allowing the evolution of all the intricate shear zone fabrics. The Ortlepp shears are, however, well replicated by the shear zones that develop in experiments where strong and homogeneous samples are subjected the tri-axial loads to failure. McGarr et al. (1979) elaborates on this. The (initial) formation of the shear fracture is primarily a tensile process, with no significant shear displacement (e.g. case A above). The geometry of the shear zone is established before the strain softening phase is reached. From the experiments of Lockner et al. (1992) we note that the state of the sample is very significantly beyond the point of peak stress and failure before the shear zone is fully evolved.

One of the uncertainties we are faced with when a complex shear zone such as shown in Figure 2(a) is exposed is whether the structures represent one or a multitude of deformation events. The understanding gained from these experiments explains the observations that the extension fractures form chronologically before the breakthrough shear ruptures. The experimental results are thus consistent with the notion, but do not prove, that most of the sub-structures defining the shears evolved during one dynamic event. The uniqueness of the Ortlepp shears of the type locality lies in the fact that each of them was a one event phenomenon.

It is not clear why, in some cases, the failure process will stop before breakthrough shear rupture develops. A shear zone, such as described in case A, is certainly a weak structure. Why did it not simply fail through once it got going? Field observations of en-echelon tension gashes in rock show that this also a natural phenomenon. The loading system that does not allow breakthrough shearing must be very stiff indeed.

It appears that the extreme cases where breakthrough shear ruptures allow tens of centimetres of dynamic displacement, forming voluminous rock flour and causing catastrophic stope damage requires special circumstances - a full understanding of which is required to design such phenomena out of the life of a mine.

\section{Conclusions}

Ortlepp shears are a class of dynamic brittle shears that form in deep mines where the stress is high enough to cause failure of strong and homogenous, intact rock. They are geometrically fully defined by a combination of extension fractures and breaktrough shear ruptures. Shear zone wall lineations are the intersections of the extension fractures and the shear zone walls, oriented normal to the shear slip vector. The complex internal structure evolves, for most part, during one dynamic seismic event. 


\section{Acknowledgements}

Interest in, and understanding of, the dynamic brittle shears were inspired by the late Dave Ortlepp with whom the author had the pleasure of numerous underground visits. The kind assistance of the rock engineering staff at mines of AngloGold Ashanti where the observations were made is much appreciated.

\section{References}

Bosman, J.D. and van Aswegen, G. (2003) Dynamic failure of pillar remnants - case studies, ISRM 2003-Technology roadmap for rock mechanics, SAIMM, Johannesburg, pp. 143-149.

Brummer, R.K. (1987) Fracturing and deformation at edges of tabular excavations: development of a numerical model describing such phenomena, Unpub. PhD thesis, Rand Afrikaans University, p. 204.

Gay, N.C. and Ortlepp, W.D. (1978) The anatomy of a mining induced fault zone, Geol. Soc. Am. Bull., Part 1, 90, pp. 47-58.

Jager, A.J. and Ryder, J.A. (1999) A handbook on rock engineering practice for tabular hard rock mines, SIMRAC, Johannesburg, p. 371.

Lockner, D.A., Byerlee, J.D., Kuksenko, V., Ponomarev, A. and Sidorin, A. (1992) Observations of quasi-static fault growth from acoustic emissions, In: Fault Mechanics and Transport Properties of Rocks, Evans, B. and Wong, T-F. (editors), Academic Press, San Diego, pp. 3-31.

Logan, J.M., Friedman, M., Higgs, N., Dengo, C. and Shimamoto, T. (1979) Experimental studies of simulated fault gouge and their application to studies of natural fault zones, Proc. Conf. VIII, Analysis of Actual Fault Zones in Bedrock, U.S. Geol. Surv., Open-File Rept., 79-1239, pp. 305-343.

McGarr, A. (1971) Violent deformation of rock near deep level, tabular excavations - seismic events, Bull. Seismological Soc. Amer., 61, No. 5, pp. 1453-1466.

McGarr, A., Pollard, D., Gay, N.C. and Ortlepp, W.D. (1979) Observations and analysis of structures in exhumed mineinduced faults, U.S. Geological Survey Open File Report., 79-1239, pp. 101-120.

McGarr, A., Spottiswoode, S.M. and Gay, N.C. (1979) Observations relevant to seismic driving stress, stress drop and efficiency, J. Geoph. Res., 84, B3, pp. 2251-2261.

Ortlepp, W.D. (1997) Rock Fracture and Rockbursts - An Illustrative Study, SAIMM, Johannesburg, p. 98.

Ortlepp, W.D. (2000) A Study of Rockburst Source Mechanism, Final Project Report, GAP 524, SIMRAC, Johannesburg.

Reches, Z. and Dewers, T.A. (2005) Gouge Formation by Dynamic Pulverization During Earthquake Rupture, Earth and Planetary Science Letters, 235, pp. 361-374.

Sibson, R.H. (1986) Brecciation processes in fault zones: inferences from earthquake rupturing, Pure Appl. Geophys., 124 , pp. 159-175.

Tchalenko, J.S. (1970) Similarities between shear zones of different magnitudes, Geol. Soc. Amer. Bull., 81, pp. 41-60. van Aswegen, G. (in prep) Observational and seismological aspect of an extreme rockburst, RaSiM7.

Wibberley, C.A.J., Petit, J.-P. and Rives, T. (2000) Micromechanics of shear rupture and the control of normal stress, J. Struct. Geol., 22, pp. 411-427.

Wilson, B., Dewers, T.A., Reches, Z. and Brune, J. (2005) Particle size and energetics of gouge from earthquake rupture zones, Nature 434, pp. 749-752. 
